24. Kim HJ, Verbinnen B, Tang X, Lu L, Cantor H. Inhibition of follicular T-helper cells by CD8(+) regulatory $\mathrm{T}$ cells is essential for self tolerance. Nature. 2010;467(7313):328-332.

25. Manavalan JS, et al. High expression of ILT3 and ILT4 is a general feature of tolerogenic dendritic cells. Transpl Immunol. 2003;11(3-4):245-258.

26. Suzuki M, et al. CD8+CD45RA+CCR7+FOXP3+ T cells with immunosuppressive properties: a novel subset of inducible human regulatory $\mathrm{T}$ cells. J Immunol. 2012;189(5):2118-2130.

27. Suzuki M, Konya C, Goronzy JJ, Weyand CM. Inhibitory CD8+ T cells in autoimmune disease. Hum Immunol. 2008;69(11):781-789.

28. Li XL, et al. Mechanism and localization of CD8 regulatory $\mathrm{T}$ cells in a heart transplant model of tolerance. J Immunol. 2010;185(2):823-833.

29. Beres AJ, Haribhai D, Chadwick AC, Gonyo PJ,
Williams CB, Drobyski WR. CD8+ Foxp3+ regulatory $\mathrm{T}$ cells are induced during graft-versus-host disease and mitigate disease severity. J Immunol. 2012;189(1):464-474

30. Lerret NM, Houlihan JL, Kheradmand T, Pothoven KL, Zhang ZJ, Luo X. Donor-specific CD8+ Foxp3+ $T$ cells protect skin allografts and facilitate induction of conventional CD4+ Foxp3+ regulatory T cells. Am J Transplant. 2012;12(9):2335-2347.

31. Zhou J, Carr RI, Liwski RS, Stadnyk AW, Lee TD. Oral exposure to alloantigen generates intragraft CD8+ regulatory cells. J Immunol. 2001;167(1):107-113.

32. Nicolls MR, Coulombe M, Bolwerk A, Beilke J, Gill RG. IFN- $\gamma$ is not a universal requirement for allograft survival. Transplantation. 2002;74(4):472-477.

33. Markees TG, et al. Long-term survival of skin allografts induced by donor splenocytes and antiCD154 antibody in thymectomized mice requires
CD4(+) T cells, interferon- $\gamma$, and CTLA4. J Clin Invest. 1998;101(11):2446-2455.

34. Konieczny BT, et al. IFN- $\gamma$ is critical for long-term allograft survival induced by blocking the CD28 and CD40 ligand $\mathrm{T}$ cell costimulation pathways. J Immunol. 1998;160(5):2059-2064.

35. Hassan AT, et al. Regulation of alloantigen-mediated T-cell proliferation by endogenous interferon- $\gamma$ : implications for long-term allograft acceptance. Transplantation. 1999;68(1):124-129.

36. Minamoto K, Pinsky DJ. Recipient iNOS but not eNOS deficiency reduces luminal narrowing in tracheal allografts. J Exp Med. 2002;196(10):1321-1333.

37. Shi Y, Rehman H, Wright GL, Zhong Z. Inhibition of inducible nitric oxide synthase prevents graft injury after transplantation of livers from rats after cardiac death. Liver Transpl. 2010; 16(11):1267-1277.

\title{
Neurogenesis or non-neurogenesis: that is the question
}

\author{
Gianvito Martino, Erica Butti, and Marco Bacigaluppi
}

Neuroimmunology Unit, Institute of Experimental Neurology (INSpe), Division of Neuroscience, San Raffaele Scientific Institute, Milan, Italy.

\begin{abstract}
Neural stem/precursor cells (NPCs) that reside within germinal niches of the adult CNS have more complex roles than previously expected. In addition to their well-documented neurogenic functions, emerging evidence indicates that NPCs exert non-neurogenic functions that contribute to the regulation and preservation of tissue homeostasis under both physiological and pathological conditions. In this issue of the JCI, Mohammad et al. found that DCs efficiently patrol the CNS only when the germinal niche of the subventricular zone functions properly. Indeed, DCs traveled from the ventricles along the rostral migratory stream to the olfactory bulb (a cervical lymph node access point) to dampen anti-CNS immune responses. The authors' findings further support a non-neurogenic role for NPCs in maintaining tissue homeostasis and promoting tissue protection in the adult brain.
\end{abstract}

\section{Neurogenesis: A tale of two germinal niches}

In the adult rodent CNS, lifelong neurogenesis - the process of neuron generation from neural stem/progenitor cells (NPCs) - primarily occurs in two distinct areas of the brain (i.e., germinal niches), the subgranular zone (SGZ) of the hippocampus and the subventricular zone (SVZ) of the lateral ventricles $(1,2)$. Depending on the germinal niche, NPCs have distinct fates. Adult NPCs generated in the SGZ migrate a short distance into the granule cell layer of the dentate gyrus (DG) and become indistinguishable from preexisting cells, an activity that is considered necessary for

Conflict of interest: The authors have declared that no conflict of interest exists.

Citation for this article: J Clin Invest. 2014;

124(3):970-973. doi:10.1172/JCI74419. modulating and refining the neuronal circuits involved in hippocampus-dependent memory processing and behavior (1-3). Newly formed NPCs from the SVZ migrate along the rostral migratory stream (RMS) to the olfactory bulb (OB), where they integrate within the granule and glomerular cell layers to maintain and reorganize the OB system $(1,2)$. Recent compelling evidence challenges the limited view that neurogenic areas of the brain act solely as sources of newly formed neurons for replacement of neuronal cells in the hippocampus and $\mathrm{OB}(4)$. In fact, the exclusive neurogenic role of the SVZ has been questioned due to recent data clearly indicating that adult $O B$ neurogenesis might not have any functional significance in humans. In adult humans, 700 new neurons are added to the hippocampus each day (corresponding to an annual turnover of $1.75 \%$ of the neurons within the renewing fraction); however, retrospective birth dating has established that the majority of $\mathrm{OB}$ neurons are of the same age as the individual, and that additional neurons in the adult human OB account for less than $1 \%$ of the total neurons exchanged over a century (4).

\section{Not only for neurogenesis: SVZ-derived NPCs exhibit non-neurogenic functions}

How can we explain the apparent paradox of NPCs being produced by the SVZ, yet no evident neuron turnover in the $\mathrm{OB}$ ? One thought-provoking explanation comes from recent studies indicating that adult NPCs residing within the SVZ exert non-neurogenic functions - such as protecting and regulating homeostasis - as alternatives to cell replacement, in both physiological and pathological conditions (Table 1 and Figure 1). For example, it has been shown that SVZ-derived NPCs have phagocytic activity toward maturing neurons, which requires the intracellular engulfment protein ELMO1 to promote Rac activation downstream of phagocytic receptors (5). Additionally, SVZ-derived NPCs have been described as having a secretory protein profile (including secretion of VEGF) distinct from other brain cells and capable of modulating activation, proliferation, and phagocytosis of microglia (6). 
Table 1

Non-neurogenic functions exerted by NPCs within the SVZ in physiological and pathological conditions

\begin{tabular}{|c|c|c|c|c|c|}
\hline Condition (mice) & Effect & Cell target & Activity & Mechanism & Reference \\
\hline \multicolumn{6}{|l|}{ Physiology } \\
\hline $\begin{array}{l}\text { Adult C57BL/6; } \\
\text { Elmo1-/- }\end{array}$ & $\begin{array}{c}\text { Cell } \\
\text { phagocytosis }\end{array}$ & Neuroblasts & Regulate neurogenesis & Phagocytosis via ELM01 & 5 \\
\hline $\begin{array}{l}\text { Adult C57BL/6; } \\
\text { CX3Cr1-EGFP }\end{array}$ & $\begin{array}{c}\text { Bystander } \\
\text { neuroprotection }\end{array}$ & Microglia & $\begin{array}{l}\text { Regulate cell proliferation, } \\
\text { activation, and phagocytosis }\end{array}$ & $\begin{array}{c}\text { Secretion of } \\
\text { growth factors (VEGF) }\end{array}$ & 6 \\
\hline $\begin{array}{l}\text { Adult C57BL/6; } \\
\text { 2D2; CX3Cr1-EGFP }\end{array}$ & $\begin{array}{l}\text { Favoring } \\
\text { cell migration }\end{array}$ & DCs & $\begin{array}{c}\text { Regulate immune responses } \\
\text { within the CNS }\end{array}$ & $\begin{array}{l}\text { Migration from the } \\
\text { ventricle along the RMS }\end{array}$ & 7 \\
\hline \multicolumn{6}{|l|}{ Pathology } \\
\hline $\begin{array}{l}\text { EAE (adult C57BL/6; } \\
\text { 2D2; CX3Cr1-EGFP) }\end{array}$ & $\begin{array}{l}\text { Favoring } \\
\text { cell migration }\end{array}$ & DCs & Regulate CNS immunity & $\begin{array}{l}\text { Migration from the } \\
\text { ventricle along the RMS }\end{array}$ & 7 \\
\hline $\begin{array}{l}\text { Stroke and epilepsy } \\
\text { (WT C57BL/6; NestinTK) }\end{array}$ & $\begin{array}{c}\text { Bystander } \\
\text { neuroprotection }\end{array}$ & $\begin{array}{c}\text { Medium } \\
\text { spiny neurons }\end{array}$ & $\begin{array}{l}\text { Regulate afferent neuronal } \\
\text { excitatory transmission }\end{array}$ & $\begin{array}{c}\text { Secretion of } \\
\text { endocannabinoids (AEA) }\end{array}$ & 9 \\
\hline $\begin{array}{l}\text { Brain tumors (WT C57BL/6; } \\
\text { nestin-GFP; Trpv1--/; } \\
\text { Ccnd2---; Faah"--; SCID) }\end{array}$ & $\begin{array}{c}\text { Bystander } \\
\text { neuroprotection }\end{array}$ & $\begin{array}{l}\text { High-grade } \\
\text { astrocytoma cells }\end{array}$ & Exert a cytotoxic effect & $\begin{array}{c}\text { Secretion of } \\
\text { endovanilloids } \\
\text { (AEA, OEA, PEA) }\end{array}$ & 10 \\
\hline $\begin{array}{l}\text { Demyelination (adult } \\
\text { C57BL/6; NG2-DsRed) }\end{array}$ & Oligodendrogenesis & $\begin{array}{l}\mathrm{NG} 2^{+} \text {oligodendrocyte } \\
\text { progenitors }\end{array}$ & $\begin{array}{l}\text { Regulate formation of } \\
\text { new oligodendrocytes }\end{array}$ & $\begin{array}{l}\text { Glutamatergic synapse } \\
\text { formation with } \\
\text { demyelinated axons }\end{array}$ & 16 \\
\hline $\begin{array}{l}\text { Stroke (adult C57BL/6; } \\
\text { N4; GFAP-GFP; Thbs4ko/+) }\end{array}$ & Astrogliogenesis & Peri-ischemic area & $\begin{array}{l}\text { Support stabilization of } \\
\text { the glial scar and BBB }\end{array}$ & $\begin{array}{l}\text { Astrogliogenesis } \\
\text { promoted by THBS4 }\end{array}$ & 17 \\
\hline $\begin{array}{l}\mathrm{SCI} \text { (adult C57BL/6; } \\
\text { Foxj1-rasless) }\end{array}$ & $\begin{array}{l}\text { Astrogliogenesis; } \\
\text { bystander } \\
\text { neuroprotection }\end{array}$ & $\begin{array}{l}\text { Neurons; } \\
\text { lesion site }\end{array}$ & $\begin{array}{l}\text { Support neuronal survival } \\
\text { and structural stabilization } \\
\text { of the lesion site }\end{array}$ & $\begin{array}{l}\text { Astrogliogenesis; secretion } \\
\text { of growth factors (CNTF, } \\
\text { HGF, IGF-1, TGF- } \beta 1 \text { ) }\end{array}$ & 18 \\
\hline
\end{tabular}

AEA, arachidonoylethanolamide; CCND2, cyclin D2; CNTF, ciliary neurotrophic factor; ELMO1, engulfment and cell motility protein 1; FAAH, fatty acid amide hydrolase; N4, nestin-creERtm4; OEA, oleoyl ethanolamide; PEA, palmitoyl ethanolamide; SCI, spinal cord injury; TRPV1, transient receptor potential vanilloid; THBS, thrombospondin.

In this issue of the JCI, Mohammad and colleagues present evidence of an additional non-neurogenic homeostatic mechanism occurring within the SVZ niche (7). Using pharmacological and toxic methods, the authors identified and characterized the RMS as a pathway for DC trafficking through the CNS to the systemic immune compartment. Ablation of NPCs and the RMS with the antiproliferative agent cytosine- $\beta$-D-arabinofuranoside (ARA-c) led to DC retention in the murine brain. Furthermore, this pathway directly modulated Treg function in the cervical lymph nodes and reduced CNS-confined immune reactions. Finally, disruption of immune cell trafficking in the brains of 2D2 mice via localized infusion of the drug fingolimod, which inhibits $T$ cell trafficking, resulted in reduced CNS immune tolerance, enhanced anti-CNS autoimmune responses, and CNS-associated inflammatory diseases such as EAE (7). While chemorepulsive factor gradients seem to guide NPC trafficking toward the OB (8), it remains to be determined whether and how DCs and NPCs physically interact along the RMS.

\section{SVZ NPCs: Guardians of the brain}

Emerging data certainly support the concept that SVZ NPCs act as guardians of the brain. In fact, NPCs are capable of sensing and contrasting danger signals to trigger an inflammatory process involving the innate arm of the immune system (Figure 1). Apart from the aforementioned relationship between SVZ NPCs and DCs, a recent study indicates that SVZ NPCs might also protect striatal neurons from glutamatergic excitotoxicity by releasing endogenous endocannabinoids (e.g., arachidonoylethanolamide [AEA]), which are capable of binding to their respective neuronal receptors (CB1 and CB2) (9). This NPC-mediated protection is tuned up during CNS-compartmentalized inflammatory insults, such as those occurring in the early phase of ischemic stroke and epilepsy. In addition, SVZ NPCs may mediate suppression of high-grade astrocytomas (HGAs) by releasing endovanilloids that activate the transient receptor potential vanilloid subfamily member-1 (TRPV1) on HGA cells, thus triggering cell death and prolonging overall survival
(10). Together, these data help to explain previous results in support of the concept of therapeutic plasticity of transplanted SVZ-derived NPCs. Various approaches have consistently shown that transplanted SVZ-derived NPCs, while remaining undifferentiated, promote CNS tissue healing via secretion of immunomodulatory and neuroprotective molecules capable of reducing detrimental responses (the socalled bystander effect) (11-14).

In addition to these newly appreciated effector functions, it is remarkable that during CNS-confined pathological processes, SVZ NPCs might also alter their neurogenic differentiation default pattern in order to confine and limit tissue damage. In toxin-induced demyelination of the corpus callosum, less than $4 \%$ of newly formed SVZ-derived cells differentiate into myelinating oligodendrocytes (15); however, newly formed SVZ-derived glial precursors can promote remyelination by forming functional glutamatergic synapses with demyelinated axons (16). Astrocyte production from the postnatal SVZ niche in response to localized photothrombotic/ 
A

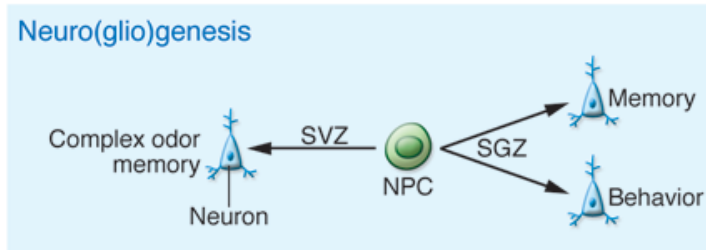

B

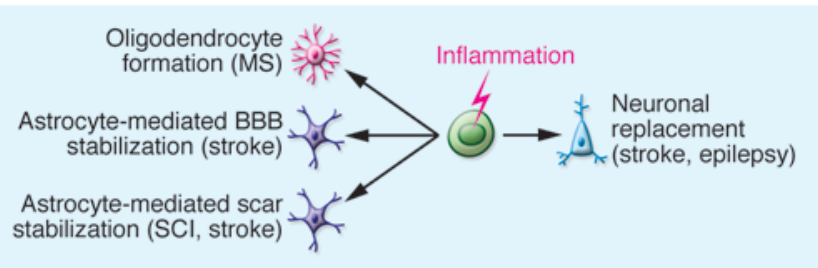

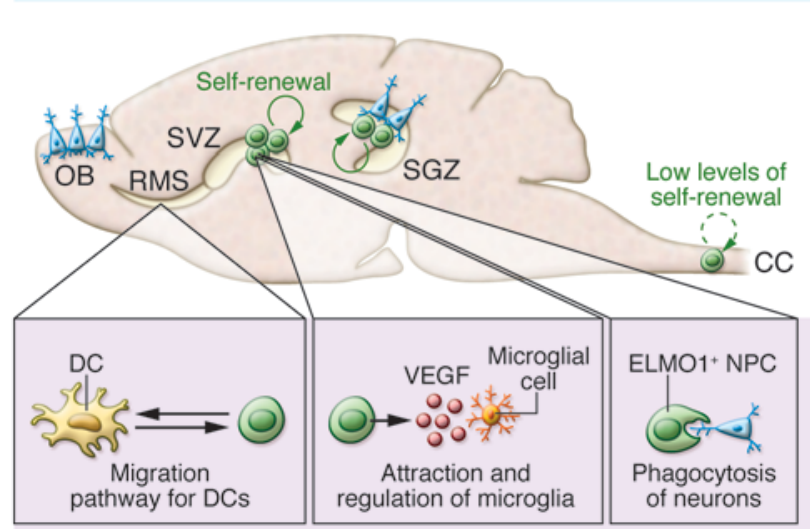

Non-neuro(glio)genesis

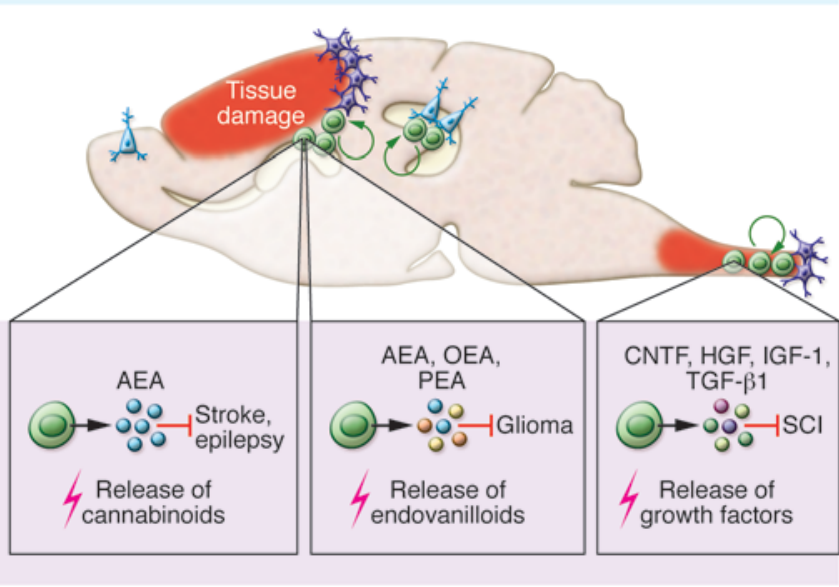

\section{Figure 1}

NPC functions during physiological and pathological conditions. (A) In physiological (homeostatic) conditions, NPCs reside within 2 main neurogenic niches, the SVZ and the SGZ, and undergo neurogenesis to maintain specific CNS circuits in the OB and in the DG. Concurrently, NPCs might exert non-neurogenic functions, such as controlling microglial cell behavior, through secretion of VEGF, and phagocytosis of maturing neurons. A recently reported non-neurogenic SVZ NPC function is the ability to act as scaffolding cells for the proper migration of DCs patrolling the CNS, allowing DC trafficking from the ventricles toward cervical lymph nodes. (B) In maladaptive (stressful) conditions, such as those occurring during pathology/inflammation, NPCs might also exert neurogenic and non-neurogenic functions aimed at maintaining or reestablishing dysfunctional CNS circuits. Depending on the pathological process, neurogenic functions are finalized to generate new neurons capable of integrating into functional circuits, whereas non-neurogenic functions are mainly aimed at limiting and/or preventing tissue damage and promoting tissue recovery. Non-neurogenic tissue restoration operates via a bimodal mechanism of action. On the one hand, SVZ NPCs do sense and contrast danger signals in order to avoid harmful inflammatory reactions through the production of soluble factors, such as cannabinoids, endovanilloids, and growth factors. On the other hand, SVZ NPCs generate new astrocytes that stabilize the glial scar and the BBB and new oligodendrocytes that promote remyelination. AEA, arachidonoylethanolamide; CC, central canal; CNTF, ciliary neurotrophic factor; OEA, oleoyl ethanolamide; PEA, palmitoyl ethanolamide; $\mathrm{SCl}$, spinal cord injury.

ischemic cortical injury (controlled by the Notch modulator thrombospondin 4 [THBS4]) has been found to stabilize the blood-brain barrier (BBB) (17). In spinal cord injury (SCI), NPC-derived astrocytes stabilize the scar and are required to restrict secondary enlargement of the lesion and further axonal loss (18). Nonetheless, NPC progeny also appear to exert a neuroprotective effect required for survival of neurons adjacent to the SCI-associated lesion. In an experimental model of epilepsy, SVZ-derived cells that migrate toward the hippocampus have been described to terminally differentiate into glial cells, but not neuronal cells (19). This process might be protective, because in temporal lobe epilepsy, newly derived neurons aberrantly migrate and integrate in the dentate hilus, exacerbating hippocampal epileptic activity (20).

\section{Conclusions}

Replacement of damaged cells does not appear to be the sole operating mechanism of SVZ-derived NPCs, and it is likely that the neurogenic and non-neurogenic behaviors of SVZ NPCs are influenced by specific characteristics of the microenvironment. Strategically, cells of the SVZ are in communication with two different microenvironments, due their contact with both blood vessels and cerebrospinal fluid (CSF) by apical processes $(8,21-23)$. Furthermore, the SVZ is very close to crucial areas of the midbrain - including basal ganglia and striatal structures - that contain GABAergic neurons capable of efficiently regulating and modulating interconnections among several cortical and subcortical brain areas (24). Finally, prior studies have demonstrated that inflammation occurring as a consequence of auto- immunity and/or traumatic and ischemic injuries might alter NPC proliferation and differentiation characteristics in a noncell-autonomous fashion (25).

The study by Mohammad and colleagues describes a role for SVZ-derived NPCs in regulating immune trafficking in the CNS (7). It is tempting to speculate that endogenous SVZ NPCs maintain and/or restore CNS homeostasis through both neurogenic and non-neurogenic functions. In addition to differentiating into neuronal cells, NPCs are capable of sensing danger signals coming from the periphery and producing a response settled to restraining conditions that might prove noxious for proper neural cell function.

\section{Acknowledgments}

This work was supported in part by TargetBrain (EU Framework 7 project HEALTH- 
F2-2012-279017) and NEUROKINE network (EU Framework 7 ITN project).

Address correspondence to: Gianvito Martino, Neuroimmunology Unit, Institute of Experimental Neurology (INSpe), Division of Neuroscience, San Raffaele Scientific Institute, Via Olgettina 58, 20132 Milan, Italy. Phone: 39.02.2643.4853; Fax: 39.02. 2643.4855; E-mail: martino.gianvito@hsr.it.

1. Alvarez-Buylla A, Lim DA. For the long run: main taining germinal niches in the adult brain. Neuron. 2004;41(5):683-686.

2. Zhao C, Deng W, Gage FH. Mechanisms and functional implications of adult neurogenesis. Cell. 2008;132(4):645-660.

3. Kitamura T, et al. Adult neurogenesis modulates the hippocampus-dependent period of associative fear memory. Cell. 2009;139(4):814-827.

4. Spalding KL, et al. Dynamics of hippocampal neurogenesis in adult humans. Cell. 2013;153(6):1219-1227.

5 . Lu Z, et al. Phagocytic activity of neuronal progenitors regulates adult neurogenesis. Nat Cell Biol. 2011;13(9):1076-1083.

6. Mosher KI, et al. Neural progenitor cells regulate microglia functions and activity. Nat Neurosci. 2012; 15(11):1485-1487.

7. Mohammad MG, et al. Immune cell trafficking from the brain maintains CNS immune tolerance. JClin Invest. 2014;124(3):1228-1241.

8. Sawamoto K, et al. New neurons follow the flow of cerebrospinal fluid in the adult brain. Science. 2006;311(5761):629-632.

9. Butti E, et al. Subventricular zone neural progenitors protect striatal neurons from glutamatergic excitotoxicity. Brain. 2012;135(pt 11):3320-3335.

10. Stock K, et al. Neural precursor cells induce cell death of high-grade astrocytomas through stimulation of TRPV1. Nat Med. 2012;18(8):1232-1238.

11. Martino G, Pluchino S. The therapeutic potential of neural stem cells. Nat Rev. 2006;7(5):395-406.

12. Ourednik J, Ourednik V, Lynch WP, Schachner M, Snyder EY. Neural stem cells display an inherent mechanism for rescuing dysfunctional neurons. Nat Biotechnol. 2002;20(11):1103-1110.

13. Pluchino $\mathrm{S}$, et al. Injection of adult neurospheres induces recovery in a chronic model of multiple sclerosis. Nature. 2003;422(6933):688-694.

14. Bacigaluppi M, et al. Delayed post-ischaemic neuroprotection following systemic neural stem cell transplantation involves multiple mechanisms. Brain. 2009;132(pt 8):2239-2251.

15. Menn B, Garcia-Verdugo JM, Yaschine C, Gonzalez-Perez O, Rowitch D, Alvarez-Buylla A. Origin of oligodendrocytes in the subventricular zone of the adult brain. J Neurosci. 2006;26(30):7907-7918.

16. Etxeberria A, Mangin JM, Aguirre A, Gallo V. Adultborn SVZ progenitors receive transient synapses during remyelination in corpus callosum. Nat Neurosci. 2010;13(3):287-289.
17. Benner EJ, et al. Protective astrogenesis from the SVZ niche after injury is controlled by Notch modulator Thbs4. Nature. 2013;497(7449):369-373.

18. Sabelstrom $\mathrm{H}$, et al. Resident neural stem cells restrict tissue damage and neuronal loss after spinal cord injury in mice. Science. 2013;342(6158):637-640.

19. Parent JM, von dem Bussche N, Lowenstein DH. Prolonged seizures recruit caudal subventricular zone glial progenitors into the injured hippocampus. Hippocampus. 2006;16(3):321-328.

20. Parent JM, Yu TW, Leibowitz RT, Geschwind DH, Sloviter RS, Lowenstein DH. Dentate granule cell neurogenesis is increased by seizures and contributes to aberrant network reorganization in the adult rat hippocampus. J Neurosci. 1997;17(10):3727-3738.

21. Tavazoie $M$, et al. A specialized vascular niche for adult neural stem cells. Cell Stem Cell. 2008; 3(3):279-288

22. Mirzadeh Z, Merkle FT, Soriano-Navarro M, GarciaVerdugo JM, Alvarez-Buylla A. Neural stem cells confer unique pinwheel architecture to the ventricular surface in neurogenic regions of the adult brain. Cell Stem Cell. 2008;3(3):265-278

23. Rolls A, et al. Toll-like receptors modulate adult hippocampal neurogenesis. Nat Cell Biol. 2007; 9(9):1081-1088

24. Koos T, Tepper JM. Inhibitory control of neostriatal projection neurons by GABAergic interneurons. Nat Neurosci. 1999;2(5):467-472.

25. Pluchino $S$, et al. Persistent inflammation alters the function of the endogenous brain stem cell compartment. Brain. 2008;131(pt 10):2564-2578.

\title{
Dangerous liaisons: flirtations between oncogenic BRAF and GRP78 in drug-resistant melanomas
}

\author{
Shirish Shenolikar
}

Program in Cardiovascular and Metabolic Disorders, Duke-NUS Graduate Medical School Singapore, Singapore.

\begin{abstract}
$B R A F$ mutations in aggressive melanomas result in kinase activation. BRAF inhibitors reduce $\mathrm{BRAF}^{\mathrm{V} 600 \mathrm{E}}$ tumors, but rapid resistance follows. In this issue of the JCI, Ma and colleagues report that vemurafenib activates ER stress and autophagy in $\mathrm{BRAF}^{\mathrm{V} 600 \mathrm{E}}$ melanoma cells, through sequestration of the ER chaperone GRP78 by the mutant BRAF and subsequent PERK activation. In preclinical studies, treating vemurafenib-resistant melanoma with a combination of vemurafenib and an autophagy inhibitor reduced tumor load. Further work is needed to establish clinical relevance of this resistance mechanism and demonstrate efficacy of autophagy and kinase inhibitor combinations in melanoma treatment.
\end{abstract}

\section{Protein kinases and cancer}

Molecular analyses of human tumors have highlighted the numerous mutations in protein kinase genes that contribute to the development of cancers. For example, the gene encoding BRAF kinase is mutated in more than $60 \%$ of

Conflict of interest: The author's research is supported in part by an Academic Center of Excellence (ACE) Award from GlaxoSmithKline Inc

Citation for this article: J Clin Invest. 2014; 124(3):973-976. doi:10.1172/JCI74609. melanomas, the most aggressive human skin cancer. Indeed, a mutation that results in a single amino acid substitution, V600E, accounts for $90 \%$ of identified $B R A F$ mutations. It is worth noting that this "oncogenic" BRAF (BRAFV600E) is present in many melanocytic nevi, which are benign neoplasias that can persist for decades without transitioning to malignancy (1). The fact that

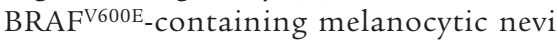
are not intrinsically aggressive hints that additional steps - such as acquisition of further mutations, metabolic reprogramming (2), or alterations in other cellular processes - are required for conversion of the proliferative melanocytes into full-fledged malignant melanomas. This raises the exciting possibility that understanding some of the internal brakes on malignancy will yield novel treatments for melanoma that fails to respond to most current anticancer therapies.

Cancer-promoting mutations frequently result in constitutive activation of the mutant kinase, which has prompted pharmaceutical companies to develop kinase inhibitors to slow or reverse the oncogenic process (3). However, the networks of signaling pathways that control cell growth in normal and cancer cells means that most kinase inhibitors are cytostatic, causing cell cycle arrest rather than cell death. Some kinase inhibitors, however, show spectacular results in eradicating tumor cells. For example, the BCR-ABL tyrosine kinase inhibitor ima- 